\title{
EDITORIAL
}

\section{In This Issue: Trade-Offs, Time Use, Depression Care}

\author{
Kurt C. Stange, $M D, P b D$, Editor \\ Conflicts of interest: none reported \\ Ann Fam Med 2005;3:482-483. DOI: 10.1370/afm.415.
}

I $\mathrm{n}$ this issue, we feature an essay ${ }^{1}$ and 2 editorials ${ }^{2,3}$ that debate the appropriate balance between investing in developing new technologies vs devoting resources toward improving systems of care to deliver services already known to be effective.

In an interesting empirical twist on this topic, Alper and colleagues evaluate a new technology for bringing synthesized evidence to answer physicians' clinical questions. ${ }^{4}$ This randomized controlled trial (RCT) shows the feasibility of providing point-of-care information that alters patient care.

Two novel studies involving medical student research fellows as direct observers examines how family physicians spend time outside the examination room. Finding a similar percentage of time spent on face-to-face patient care $(55 \%$ and $61 \%)$, these studies show substantial devotion to patient care activities that may not be adequately reflected in current billing codes and reimbursement procedures. ${ }^{5,6}$ These studies also provide a model for engaging medical students in direct observation research.

Another pair of studies examines suicidal ideation among depressed primary care patients. The study by Schulberg et al finds a low risk of suicide among depressed primary care patients. ${ }^{7}$ This risk remains fairly stable over 6 months of follow-up. A randomized study by Nutting and colleagues shows that brief physician and nurse training in primary care can double the rate of initial detection of suicidal ideation. ${ }^{8}$

A study of physician quality of life finds that physicians in independent practice (vs being employees) work longer hours but report greater satisfaction and less intention to leave practice. ${ }^{9}$ In the face of diminishing student interest in family medicine, these findings have implications for retaining and enhancing the effectiveness of our current primary care work force.

Although an emerging body of research examines medical errors, the effect of patients' experience of a preventable problem has not been examined. The qualitative study by Elder and colleagues finds that among patients who have lived through a preventable medical problem, anger is common, as is mistrust and resignation. ${ }^{10}$ This analysis classifies patient responses into 4 categories: avoidance, accommodation, anticipation, or advocacy, each with different implications for subsequent health care.

A new patient literacy screening instrument is subjected to a rigorous evaluation in a methodology study by Weiss and colleagues. ${ }^{11}$ Given the frequency of low literacy and its effect on health and health care, this instrument deserves attention for both research and clinical use.

An essay by Buetow argues that "care" is defined by "coprovision" in which clinicians and patients each contribute expertise in their domain. ${ }^{12}$ This analysis provides an alternative to both medical paternalism and patient consumerism through mutual responsiveness and responsibility.

We invite all Annals readers to participate in the online discussion of these articles at http://www. annfammed.org.

To read or post commentaries in response to this article, see it online at http://www.annfammed.org/cgi/content/full/3/6/482.

\section{References}

1. Woolf SH, Johnson R. The break-even point: when medical advances are less important than improving the fidelity with which they are delivered. Ann Fam Med. 2005;3:545-552.

2. Kravitz R. Doing things better vs doing better things. Ann Fam Med. 2005;3:483-485.

3. Teutsch SM, Berger M. Misaligned incentives in America's health: who's minding the store? Ann Fam Med. 2005;3:485-487.

4. Alper BS, White D, Ge B. Physicians answer more clinical questions and change clinical decisions more often with synthesized evidence: a randomized trial in primary care. Ann Fam Med. 2005;3:507-513.

5. Gottschalk A, Flocke SA. Time spent in face-to-face patient care and work outside the examination room. Ann Fam Med. 2005;3:498-493. 
6. Gilchrist V, McCord G, Labuda-Schrop S, et al. Physician activities during time out of the examination room. Ann Fam Med. 2005;3:494-499.

7. Schulberg HC, Lee PW, Bruce ML, et al. Suicidal ideation and risk among primary care patients with uncomplicated depression. Ann Fam Med. 2005;3:523-528

8. Nutting PA, Dickinson LM, Rubenstein L, Elliott CE, Keeley RD. Improving detection of suicidal ideation among depressed patients in primary care. Ann Fam Med. 2005;3:529-536.
9. Beasley JW, Karsh B, Hogenauer M, Marchand L, Sainfort F. What is the quality of work life of independent vs employed family physicians in Wisconsin? A WRen Study. Ann Fam Med. 2005;3:500-506.

10. Elder NC, Jacobson J, Zink TM, Hasse L. How experiencing preventable medical problems has changed patients' interactions with primary healthcare. Ann Fam Med. 2005;3:537-544.

11. Weiss BD, Mays MZ, Martz W, et al. Quick assessment of literacy in primary care: the newest vital sign. Ann Fam Med. 2005;3:514-522.

12. Buetow SA. To care is to coprovide. Ann Fam Med. 2005:3:553-555.

\title{
EDITORIAL
}

\section{Doing Things Better vs Doing Better Things}

\author{
Richard L. Kravitz, MD, MSPH \\ Center for Health Services Research in Primary Care, University of California, Davis, Sacramento, Calif
}

Ann Fam Med 2005;3:483-485. DOI: 10.1370/afm.407.

$\mathrm{T}$ The United States spends approximately $\$ 1.5$ trillion on health care each year (about $\$ 5,700$ per person), yet we have relatively little to show for it. Population health statistics (eg, years of healthy life expectancy) place the United States somewhere between Portugal and Slovenia. ${ }^{1}$ Part of the reason for America's poor showing is that treatments known to be effective are not reliably delivered to the people who need them. The problem has been parsed many different ways, ${ }^{2-4}$ but most authorities would agree that poor access to care, flawed decision making, and error-prone implementation are the critical dimensions. There is plenty of evidence for unsatisfactory performance along all 3 lines. The situation for the poor and for ethnic minorities is, not surprisingly, worse. ${ }^{5}$ Meanwhile, our nation continues to pour money into biomedical research in the hopes of discovering cures. In their essay in this issue of the Annals, Steven Woolf and Robert Johnson ask a novel and pertinent question: what would happen if we devoted more resources to doing

Conflict of interest: none reported

\section{CORRESPONDING AUTHOR}

Richard L Kravitz, MD, MSPH

Center for Health Services in Primary Care

University of California, Davis

2103 Stockton Blvd

2226 Grange Bldg

Sacramento, CA 95817

rlkravitz@ucdavis.edu what we do better, rather than looking for new things to do. They introduce a new term, fidelity, to describe what others have called integration-making sure that what we know to be beneficial actually gets done. The answer-that we may well be better off if we shifted resources from discovery to fidelity-may surprise some people.

Woolf and Johnson do some calculations that show how, in at least 2 cases, increasing the delivery of treatments with known effectiveness would save more lives than discovering new treatments, unless those new treatments represented astounding advances over current therapy. In one example, new antiplatelet treatments to prevent stroke would have to be $74 \%$ more effective than aspirin to generate the same benefits as a behavioral intervention designed to increase aspirin use from $58 \%$ of eligible patients (which is the current national average, according to a RAND study ${ }^{6}$ ) to $100 \%$. In another example, new cholesterol-reducing agents would need to be 3 times as potent as current statins to equal the mortality benefits of ensuring that the older statins are actually taken by $100 \%$ of eligible patients.

Lamentations about lack of scientific progress against dread diseases are not new. The war on cancer, for example, strikes some as a quagmire. ${ }^{7}$ What is bracing here are the cold, hard numbers. They show explicitly the trade-offs between discovery and integration.

Resources committed to one front may be opportunities lost on the other.

A few of the authors' assumptions and some of their logic invite scrutiny. For a variety of reasons, the esti- 